\title{
Research on Exploration Tourism Resources Development in Western Sichuan Based on RMP Analysis
}

\author{
Chi Panpan \\ School of Management, Shanghai University, Shanghai, China \\ Email: 1213949813@qq.com
}

\begin{abstract}
Adventure tourism is one of the most popular forms of tourism. This paper takes western Sichuan as an example, adopts the research methods of literature, questionnaire, logic analysis and so on. And applies RMP theory to analyze the resources, market and products of exploration tourism development in western Sichuan.This paper puts forward the specific ideas of exploration tourism development in western Sichuan: based on spacal resource, put market demand as the guide and the adventure, excitement, entertainment as the main line to carry out theme, type, function and form innovation. In addition, establish the exploration project, exploration depth exploration project and cultural products project three sales tourism brand. Based on this, the author designs and puts forward some strategies for adventure tourism development in western Sichuan. It provides reference basis for realizing healthy and long-term development and adventure tourism development in western Sichuan.
\end{abstract}

Keywords: RMP analysis, adventure tourism, western Sichuan, the development of research

\section{Introduction}

With the development of the times and the progress of people's living standards, the mass tourism products with a single sightseeing level can no longer meet people's psychological needs for tourism and leisure, but seek for in-depth tourism products with a high degree of participation and experience. Adventure tourism is developed under such a background. Adventure tourism means that adventure tourists with outdoor sports technology can get a certain sense of novelty and excitement by carrying out adventure or experience activities that are dangerous and challenging to a certain extent when they are in a natural environment with few people. According to the intensity and risk of adventure tourism, it can be divided into hard adventure and soft adventure. Western Sichuan has its unique and rich natural and cultural tourism resources. The peculiar geology, rare plants and animals, national characteristic culture all provide the reliable resource base for developing the adventure tourism.

RMP analysis theory means that tourism products are the center of regional tourism development, $\mathrm{P}$ (product analysis)is carried out on the basis of $\mathrm{R}$ (resourse analysis) and $\mathrm{M}$ (market analysis), and finally to develop framework with tourism products as the center.

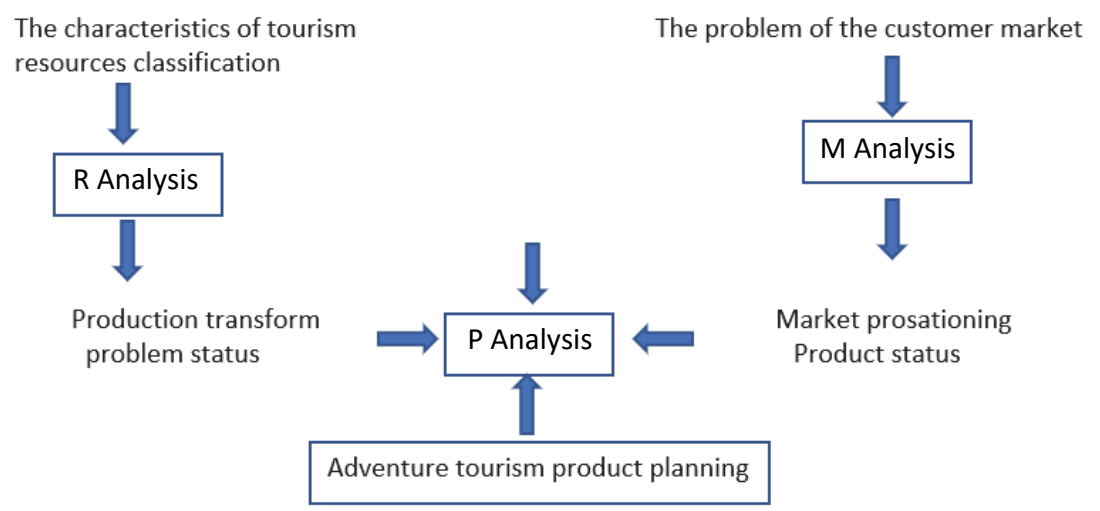

Figure 1. Frame diagram 
Based on the RMP theory, this paper makes an in-depth analysis of the adventure tourism resources in western Sichuan from the perspectives of resources, market and products. To explores a new path of adventure tourism resources in western Sichuan in order to promote local economic development. The specific framework is shown in Figure 1.

\section{RMP Analysis of Adventure Tourism Resources in Western Sichuan}

\subsection{Analysis of Adventure Tourism Resources in Western Sichuan ( $R$ analysis)}

Scenic spots in western Sichuan include three world natural heritages - Jiuzhaigou, Huanglong and siguniang mountain, as well as Wolong national nature reserve. It also includes the famous ancient city of Kangding, Taoping Qiang village, Seda Buddha college, Miaro scenic spot, the first bend of the Yellow River and the western Sichuan plateau. In addition, there are also many recently rising tourist attractions that attract a large number of tourists (JinYin Xiong, 2016). These tourism resources have great attraction to adventure tourists who like fresh and exciting and pursue the beauty of nature. Through data collection, the author sorted out some exploration tourism resources in western Sichuan, and classified exploration tourism resources in western Sichuan according to "Classification, Investigation and Evaluation of Tourism Resources", as shown in table 1.

Table 1. Classification and distribution of adventure tourism resources in western Sichuan

\begin{tabular}{|c|c|c|c|}
\hline $\begin{array}{l}\text { Types of adventure } \\
\text { tourism resources }\end{array}$ & \multicolumn{2}{|c|}{ Types of segmentation subclass } & \multirow{2}{*}{$\begin{array}{c}\text { The adventure } \\
\text { category }\end{array}$} \\
\hline \multirow{11}{*}{ Land Scenery } & \multirow{2}{*}{$\begin{array}{c}\text { Comprehensive nature tourism } \\
\text { destination }\end{array}$} & Miro scenic spot & \\
\hline & & Scenic Spot of Daocheng Yading & Soft adventure \\
\hline & Sedimentation and structure & Siguniang mountain & Soft adventure \\
\hline & \multirow{6}{*}{$\begin{array}{c}\text { geological and geomorphic } \\
\text { processes trace }\end{array}$} & Gonggar snow mountain & Hard adventure \\
\hline & & The white bear ditch & Soft adventure \\
\hline & & Bamboo root bifurcation channel & Soft adventure \\
\hline & & Western Sichuan Plateau & Hard adventure \\
\hline & & Huang Long scenic spot & Soft adventure \\
\hline & & The three ao snow mountain & Hard adventure \\
\hline & \multirow{2}{*}{ Naturally fluctuating relic } & The Conch's ditch & Soft adventure \\
\hline & & Haizishanzimeihu & Soft adventure \\
\hline \multirow{5}{*}{$\begin{array}{c}\text { The waters of the } \\
\text { landscape }\end{array}$} & reach & The Yellow River bends eighteen times & Hard adventure \\
\hline & \multirow{4}{*}{ Natural lakes and ponds } & Tianmu lake & Soft adventure \\
\hline & & Mugecuo & Soft adventure \\
\hline & & Hehuahaiyuelaingwan & Soft adventure \\
\hline & & Xinluhai & Soft adventure \\
\hline
\end{tabular}

According to the national standard "Scenic and historic interest area planning code", based on the classification of scenic resource types, there are 4 scenic resources of level 5, 6 scenic resources of level 4 and 6 scenic resources of level 3 in the listed adventure tourism in western Sichuan (table 2 and figure 2).

Table 2. Exploration tourism resources in western Sichuan

\begin{tabular}{ccc}
\hline Grade & Quantity & Ratio \\
\hline Level 5 & 3 & $18.7 \%$ \\
Level 4 & 5 & $31.3 \%$ \\
Level 3 & 8 & $50 \%$ \\
\hline
\end{tabular}




\section{Western Sichuan region part of the exploration scenic spot grade composition

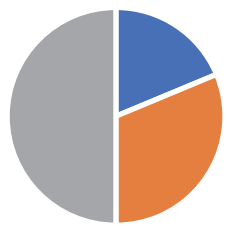 \\ - level 5 - level 4 - level 3}

Figure 2. Exploration tourism resources in western Sichuan

On the basis of national standards, the relevant tourism resources in western Sichuan are classified as above. So western Sichuan region adventure tourism resources are rich and varied. Hundreds of millions of years of geological movement, has created the western Sichuan magnificent and precipitous geological scenery, the unique human geography, has bred the rich cultural accumulation. Such as Huanglong temple, Jiuzhaigou, etc. Besides, there are also many famous rivers and lakes, which are the best places for sightseeing, rafting and other adventure tourism activities. It is very attractive natural landscape, but also an excellent choice for tourists to return to nature and enjoy the natural scenery. In addition, exploration tourism resources of different types in western Sichuan have rich value systems. The value of exploration, artistic appreciation and scientific investigation is significant.

\subsection{Market Analysis of Adventure Tourism in Western Sichuan (M Analysis)}

Table 3. Demand elasticity of common domestic tourism products

\begin{tabular}{lllll}
\hline Tourist project & $\begin{array}{l}\text { Short \& medium } \\
\text { sightseeing }\end{array}$ & $\begin{array}{l}\text { Weekend short } \\
\text { sightseeing }\end{array}$ & $\begin{array}{l}\text { Long \& distance } \\
\text { sightseeing }\end{array}$ & $\begin{array}{l}\text { Adventure } \\
\text { tourism }\end{array}$ \\
\hline Time & shorter & shorter & longer & long \\
Cost & small & more & more & much \\
hierarchy of needs & base layer & Higher layer & A higher layer & Very high layer \\
Elasticity demand & small & small & large & large \\
\hline
\end{tabular}

Demand Elasticity. The four factors mentioned in Table 3, namely time expenditure, money expenditure, demand level and demand elasticity, fully express people's demand and desire for adventure tourism, among which the demand elasticity of adventure tourism products is the most significant. Adventure tourism is an emerging tourism product integrating entertainment, art, participation, self-satisfaction and other functions. It can be seen that the adventure tourism products in western Sichuan region not only have the characteristics of sightseeing tourism products, but also have the characteristics of cultural tourism products, which belong to the high-level tourism products, with great demand elasticity.

Tourist Income. According to "Sichuan Statistical Bulletin on National Economic and Social Development 2018", In 2018, the tourism revenue of western Sichuan region reached 1011.28 billion yuan, up 13.3 percent over the previous year. It has received 700 million domestic tourists, up 4.9 percent; Domestic tourism revenue reached 1001.27 billion yuan, up 13.5 percent. It received 3.698 million inbound tourists, up 10.0 percent; Foreign exchange revenue from tourism reached us $\$ 1.51$ billion, up $4.5 \%$. Statistics in table 4 show that in 2018, western Sichuan received 200 million tourists from home and abroad, up $95.4 \%$ year on year. It shows that the exploration tourism resources in western Sichuan are promising. 
Table 4. The number of tourists total revenue and growth rate in western Sichuan form 2014-2018

\begin{tabular}{llll}
\hline Year & $\begin{array}{l}\text { Number of tourists } \\
\text { (Thousands of people) }\end{array}$ & rate of increase & $\begin{array}{l}\text { tourist income (a } \\
\text { hundred million) }\end{array}$ \\
\hline 2014 & 6844.19 & $7.9 \%$ & 512.04 \\
2015 & 8036.88 & $17.4 \%$ & 644.25 \\
2016 & 9142.93 & $6.2 \%$ & 753.8 \\
2017 & 11716.33 & $28.1 \%$ & 817.9 \\
2018 & 19089.57 & $62.9 \%$ & 923.6 \\
\hline
\end{tabular}

Note: from the statistical bulletin of national economic and social development of Ganzi Tibetan autonomous prefecture, Liangshan Yi autonomous prefecture and aba Tibetan and Qiang autonomous prefecture from 2014 to 2018

Source Market. In recent years, adventure tourism in western Sichuan has developed well, But the price of travel products is not clear, To better meet the demand of tourists, this paper designs the adventure tourism tourists questionnaire about western Sichuan region, A total of 350 questionnaires were distributed and 327 were recovered, with an effective rate of $93.4 \%$, of the 327 respondents, men outnumbered women, with men accounting for 79 percent, Age distribution is mainly between 26 and 45 years old, $83 \%$ of the total number of the survey, belongs to the young and middle-aged tourism consumption market. Through the effective data analysis of the questionnaire, tourists mainly travel to challenge themselves and pursue the nature, accounting for $41 \%$ and $38 \%$. Travel for the form of traveling alone or friends, the main means of transportation for driving or hiking; Most of the tourists stay for a long time, usually more than 3 days. The tourism consumption amount is about 3000 yuan, accounting for $34 \%$. In terms of the preference of adventure tourism, $28 \%$ of tourists are most interested in the products of hiking adventure routes, while the rest prefer adventure products such as bungee jumping and jungle exploration.

\subsection{Analysis of Adventure Tourism Products in Western Sichuan (P Analysis)}

Tourism Development Status in Western Sichuan. Western Sichuan, with its unique and beautiful natural scenery, has attracted a large number of film and television places to set the scene here, and also to actively promote tourism. Such as Daocheng Yading, in the most mysterious area of the scenic spot, actively absorb the heat of hot love movies, carry out the publicity of hot spots where couples propose. At the same time, depending on natural advantages to built such as landscape, bungee jumping, rafting and other adventure projects; With the help of high mountains, dense forests, ravines and ravines, create a jungle crossing project, through 10,000 mu of mountains, arrow bamboo, experience the thrill of encountering pandas and other wild animals; Lofty and beautiful mountains and rivers, mysterious and romantic trench have also developed the corresponding exploration products. Western Sichuan is good at using its natural advantages skillfully to increase development efforts, which greatly improves tourists' enthusiasm and participation in adventure projects.

Based on the market analysis, tourism is a pillar industry of Sichuan province and western Sichuan, but frequent earthquakes in recent years have brought impacts to Sichuan province and western Sichuan. After the 2008 wenchuan earthquake, the Sichuan provincial tourism administration estimated that the direct loss to Sichuan's tourism industry was more than 50 billion yuan. After the jiuzhaigou earthquake in 2017, a total of 32,976 tickets had been returned to jiuzhaigou by August, with a loss of 7.25 million yuan based on the peak season ticket price of 220 yuan per person. In addition, the damage to the local catering and accommodation industries is not yet assessed. In addition to the economic impact, some tourists are also afraid of Sichuan province and the western Sichuan region due to the earthquake, and they will be more cautious in choosing the western Sichuan tourist destinations. However, adventure tourists are always in pursuit of novelty and excitement. The author believes that the scenic spot should increase publicity efforts, do a good job in post-earthquake recovery, eliminate tourists' misunderstanding of the earthquake and their fear of the region, so as to promote the enthusiasm of explorers.

Problems of Adventure Tourism Products in Western Sichuan. First, tourism product development conditions are relatively backward. This mainly refers to the economic investment conditions 
and supporting facilities conditions are relatively backward, indicating that the region's adventure tourism related safety and other supporting facilities need to be developed. Adventure tourism is an activity with a very high degree of participation by tourists. The essence lies in the tourists' personal experience and the mystery of the unknown world. However, all these explorations are based on safety, and the unpredictability of roads and the mystery of the environment may bring safety risks. Second, tourism products of a single type. The current tourism products in western Sichuan are mainly tourist products and lack of integration, comprehensive grade is low. Adventure tourism resource is relatively special, development degree is more difficult, some of the resources available for exploration are difficult to fully exploit, In western Sichuan, there are many resources of this type, which limits the development of resources. The competition of the same type of tourist destination has no advantage, and it is difficult to meet the diversified needs of consumers.

\section{Exploration Tourism Development in Western Sichuan}

\subsection{Exploration Tourism Development Ideas in Western Sichuan}

The exploration of adventure tourism resources in western Sichuan can be based on resources and market-oriented, with exploration, stimulation and entertainment as the main line to carry out theme, type, function and form innovation, and construct exploration project exploration, exploration in-depth experience and exploration cultural sales of three tourism products. Combined with aboved market analysis, most of the visitors to western Sichuan area is for the young, so can be integrated into the local unique culture of the Sichuan-tibet, combined with powerful technology strength, using science and technology and the three dimensional animation, through the big screen, rendering of Sichuan region unknown charm of the depths of the mountains, to inspire visitors to explore the enthusiasm, to give visitors a visual feast. At the same time, some man-made exploration projects, such as bungee jumping, can help tourists better integrate into them. In addition to tourist photos, the local scenic spot can design some cultural products with local characteristics, such as clothing and sheepskin drum, for tourists to buy souvenirs.

\subsection{Exploration Tourism Development Strategy in Western Sichuan}

We will improve the government management system and improve relevant laws and regulations. As indicated above, adventure projects, safety first. Adhere to the principle of "government-led, enterprise main body, market operation", ensure the absolute safety of relevant equipment and strengthen supervision, the implementation of the unit is not perfect punishment, to ensure the tourist experience; In addition, according to the specific situation of the western Sichuan, integration between content and different levels of laws and regulations, build legal frame of western Sichuan adventure tourism fast development, such as adventure tourism resources property rights, licensing regulations, environmental protection and management regulations, anti-unfair competition law, adventure tourism qualification authentication, adventure travel security laws and regulations, etc.

Strengthen regional cooperation to solve the single product. The western Sichuan region is close to Tibet and the neighboring provinces are also extremely rich in resources, which can strengthen regional cooperation. The "exploration culture tourism development office", led by government leaders and jointly participated by relevant departments of exploration, tourism and culture, was established to take overall consideration of the project introduction, coordination and resource integration of western Sichuan tourism and formulate special development plans. In line with the principle of "grand tourism and sustainable development", relevant government departments guide relevant industries to cooperate closely, eliminate industrial barriers and coordinate development, so as to achieve win-win results between adventure tourism and related industries.

Expand sales channels and establish brand image. Build the "Internet + "Sichuan west service platform, integrate resources, projects, enterprises, products and other information through the information sharing platform, and improve the overall service level in marketing, sales, development, law and public relations. Promote the overall development of adventure tourism. 


\section{Conclusion}

With the frequent earthquakes in Sichuan in recent years, some exploration scenic spots in western Sichuan have encountered crisis. How to further explore and protect exploration tourism and exploration tourism resources in western Sichuan has become a hot topic to be solved urgently. The exploration tourism development in western Sichuan region is based on high quality natural resources and has its own ethnic customs. This paper applies RMP theory, takes the market as the orientation, takes the tourist experience as the breakthrough. To deeply developed the core of adventure tourism and optimized to create a unique adventure brand in western Sichuan. To enhance tourists' awareness of the brand, to achieve the optimization and upgrading of tourism structure in western Sichuan. Build western Sichuan into one of the most distinctive tourism brands in Sichuan, and provide the basis for building a world-class tourism area.

\section{Reference}

1. Manuel Sand; Sven Gross:Tourism research on adventure tourism - Current themes and developments, Journal of Outdoor Recreation and Tourism,2019.

2. BihuWu. RMP analysis of regional tourism development -- a case study of luoyang city, henan province [J]. Geography research, vol.01,PP.104-111.,2001.(in Chinese)

3. Jinyin Xiong:Development and utilization of agricultural ecotourism resources in western Sichuan plateau. Agricultural resources and regionalization in China,vol.37,no.3,pp.217-220,2016.(in Chinese)

4. Mingming Ren:Research on exploration tourism development of changbai mountain tourist area [D]. Southwest University,2008. (in Chinese)

5. Tao Wu, Qiong Wang:Analysis on the development prospect of adventure tourism in western Sichuan [J] Tourism Overview,vol.271,no.5,pp.37-38,2018. (in Chinese)

6. Xiaolu Ma: Development strategy of tourism resources in ecologically fragile areas in western Sichuan [J]. Economic Research Guide,vol.16,pp.243-244,2014. (in Chinese)

7. Kehong $\mathrm{Yu}$,xingquan $\mathrm{Gu}$ Based on analysis of RMP city sports leisure tourism development and management[J]. journal of beijing university of physical education,vol.30,no.5,2007. (in Chinese)

8. Ceballos Lascurain H.The Future of Ecotourism[J].Mexico Journal.vol.2,pp.13-14.1987

9. Yanyan Ren: Evaluation and construction feasibility analysis of shenzhen dapeng peninsula scenic tourism resources [J]. green science and technology, vol.19,2019. (in Chinese)

10. Xioahui Bao:Discussion on the methods of impact assessment for eco-tourism projects in nature reserves[J].Journal of chifeng college vol.5,pp.1-6,2005. (in Chinese) 